\title{
Development of Software for the Microcontroller Based Automated Drip Irrigation System Using Soil Moisture Sensor
}

\author{
N.V. Gowtham Deekshithulu*, G. Ravi Babu, \\ R. Ganesh Babu and M. Siva Ramakrishna \\ College of Agricultural Engineering, Bapatla, Andhra Pradesh, India \\ *Corresponding author
}

\begin{tabular}{|l|}
\hline Ke y w o r d s \\
8051 \\
microcontroller, \\
$\begin{array}{l}\text { Keil } \mu \text { vision 3, } \\
\text { Solenoid valve, Soil } \\
\text { moisture sensor }\end{array}$ \\
\hline Article Info \\
\hline $\begin{array}{l}\text { Accepted: } \\
\text { 12 December } 2017 \\
\text { Available Online: } \\
\text { 10 January 2018 }\end{array}$ \\
\hline
\end{tabular}

\section{Introduction}

Irrigation by help of freshwater resources in agricultural areas has a crucial importance. Because of highly increasing demand for freshwater, optimal usage of water resources has been provided with greater extent by automation technology and its apparatus such as solar power, drip irrigation, sensors and

\section{A B S T R A C T}

Many areas of agricultural fields are effectively over or under irrigated due to spatial variability in water infiltration and runoff of rainfall and irrigation, crop water use and irrigation depth. Under-irrigated areas are subject to water stress, resulting in production loss, while over-irrigated areas suffer from plant disease and nutrient leaching. This research presents the design of microcontroller based soil moisture sensor was developed at College of agricultural Engineering, Bapatla. It was developed for adaption of Indian farmers to facilitate high water use efficiency by replacing hardware components with software functions which allows farmers to apply the right amount of water at the right time. The developed sensor 8051 microcontroller is designed using keil $\mu$ vision 3 software for maximum of four sensors present in each field and controls the water supply in the field to be irrigated using solenoid valve. The sensor present in each field stops the pump automatically through microcontroller when the field reached to its field capacity and the motor will be switched on automatically when soil moisture reaches $70 \%$ of field capacity. Microcontrollers then supply water to that particular field for which water requires, till the sensors are deactivated again. The experimental field with an area of $1330 \mathrm{sq} \mathrm{m}$ for sweet corn crop was selected for performance evaluation with three sub plots i.e., flood method, single row and paired row drip method. Overall yield response and water use efficiency for sweet corn crop is highest in single row drip method with $7.93 \mathrm{t} \mathrm{ha}^{-1}$ and $23.88 \mathrm{~kg} / \mathrm{ha}-\mathrm{mm}$ respectively. Water applied in drip irrigation system using soil moisture sensor was found to be $332 \mathrm{~mm}$ instead of $520 \mathrm{~mm}$ in flood method for sweet corn and $36 \%$ water saving was observed. The total cost of the microcontroller based soil moisture sensor was Rs. 3755 as compared to the Rs. 1 lakh worth commercial available automated system.

remote control (Mahir and Semih, 2011). Many of the commercially available sensors, valves and modules assembled for irrigation system networks are too complex and costly to be feasible for site specific management of fixed irrigation systems which are not adopted by the Indian farmers (Prasad et al., 2012). The efficiency of various management decisions depends on accurate measurements, 
which in turn depends on the accuracy of the sensor. Therefore, appropriate low cost technology has to be developed to facilitate high water use efficiency.

It's hardly possible that every farmer must possess the perfect knowledge about growing specifications of plants in case of water supply. So to help them we are making an attempt by introducing our project low cost microcontroller based automated drip irrigation system using soil moisture sensors. By using sensors in our work we will make them aware about changing conditions of moisture level according to weather in relation to changing conditions of soil moisture they will be able to schedule the proper timing for water supply. Automated irrigation systems can increase crop yields, save water usage, energy and labour costs as compared with manual systems (Mulas, 1986). Automated irrigation system also facilitates high frequency and low volume irrigation (Noble et al., 1999).

The main aim of the research is to develop and to test a low cost equipped microcontroller for management of drip irrigation systems with soil moisture sensors. Such a system can be cost effective monitoring control systems for growers.

\section{Materials and Methods}

\section{Microcontroller 8051 unit}

The microcontroller incorporates all the features that are found in microprocessor. The microcontroller has built in ROM, RAM, input output ports, serial port, timers, interrupts and clock circuit. A microcontroller is an entire computer manufactured on a single chip. The microcontroller detects the moisture level of the soil with the help of four sensors. A display unit is interfaced with the MCU for user information and displaying the condition of the field. MCU operates the motor as per the moisture level in the soil. The software developed in the ' $\mathrm{C}$ ' language was incorporated into the microcontroller by using dumper.

\section{Interfacing LCD to microcontroller}

The LCD (Liquid Crystal Display) is used to display the status of the system. Software communication takes place between the controller of the LCD and the microcontroller.

\section{Keil $\mu$ Vision 3}

Using keil $\mu$ vision 3 software, the code is developed in $\mathrm{C}$ language for four sensors to the operation of automated drip irrigation system. The developed code is saved in hex file and this hex file is dumped into the microcontroller using flash magic software.

\section{Design of low cost microcontroller based soil moisture sensor}

For the development of microcontroller based soil moisture sensor, the following components are required as given in Table 1. These components are purchased and assembled in the box having board as shown in Figure 1.

\section{Working principle involved in soil moisture sensor}

In this experiment, sensors will detect the soil moisture in the root zone depth (agricultural field) and supply water to the field when requires irrigation water. The developed sensor 8051 microcontroller based design which controls the water supply to the field using solenoid valves. The sensor present in the field, stops the pump automatically through microcontroller when the soil moisture of the field reached to field capacity. Once the field reaches to $70 \%$ of field capacity 
$(8.47 \%)$, sensors sense the requirement of water in the field and send a signal to the microcontroller. Microcontrollers then supply water to that particular field for which water requires, till the sensors are deactivated again.

\section{Results and Discussions}

\section{Development of low cost microcontroller based soil moisture sensor}

In the development of low cost microcontroller based soil moisture sensor, $5 \mathrm{v}$ DC power supply is needed for all electronic operations. Step down transformer, rectifier, voltage regulator, and filter circuit are required for generation of $5 \mathrm{v}$ DC power. The total cost of the microcontroller based soil moisture sensor was Rs. 3755 as compared to the Rs. 1 lakh worth commercial available automated system. The microcontroller based soil moisture sensor works on the circuit diagrams as shown in the Figure 2, 3, 4 and 5.

The deficiency of water in the field is sensed by the op-amp based sensor. Whenever there is need of water in the particular field, the high signal ("1") appears on the output pin of the sensor of that particular field. The output pins of all the sensors are connected to the PORT 2 of microcontroller. The high signs 1 (logic 1) from the sensor is entertained by the microcontroller at a particular pin.

By knowing the position of the pin on which signal appears, the microcontroller switch ON the RELAY (i.e. Water pump) connected at PORT 0. Now water starts run into the required field by opening of solenoid valve. After completion of watering i.e. field soil moisture content reaches to the field capacity, the sensor sends low signal (logic 0) to microcontroller. When microcontroller receives this signal, it switches OFF the water pump. Now microcontroller starts sensing the signal at PORT 2. In developing the software included in the microcontroller program was planned for the maximum of four sensors. Like this process is continued and get the automatic irrigation to the fields by using intelligent device microcontroller 8051 in which source code is dumped. A microcontroller is used to control the operation along with relay switch and pump.

\section{Design of power supply}

The AC (Alternate Current) voltage, typically $220 \mathrm{~V}$ is connected to a transformer which steps that AC voltage down to the level of the desired DC (Direct Current) output. A diode rectifier provides a full wave rectified voltage that is initially filtered by a simple capacitor filter to produce a DC voltage. This resulting DC voltage usually has some ripple or AC voltage variation. A regulator circuit removes the ripples and maintains the same DC value even if the input DC voltage varies or the load connected to the output DC voltage changes as shown in Figure 6. This voltage regulation is usually obtained using one of the popular voltage regulator IC units. There is need of $5 \mathrm{v}$ DC power supply for all electronics involved in the project.

\section{Generating a $\mu$ Vision project}

1. Start the Keil $\mu$ Vision3 application as shown in Figure 7.

2. Select New Project from the Project Menu.

3. Name the project.

4. Click on the Save Button.

5. The device window will be displayed. Select the part that will be using to test with and double click on it.

6. Scroll down and select the IC no. and Click ok. 
7. Select Yes when prompted to add the startup code to the project folder.

8. This will create a new project. The project contains a target called 'Target 1' and a source group folder associated with this target.

9. Click File Menu and select New.

10. A new window will open up in the Keil.

11. Now create a $\mathrm{C}$ file containing our application code.

12. Save the file as.c

13. Expand source group 1 and click on add files to group 'source group 1'.

14. Select.c file and click on add button.

15. Use 'Build' and 'Rebuild all target files' from the Project pull-down menu. In the Build Window it should report ' 0 Errors (s), 0 Warnings'.
16. Before simulating the code ensure that the correct crystal speed has been chosen for the particular targeted microcontroller. The AT89S52 microcontroller board uses the on-board $11.0592 \mathrm{MHz}$ oscillator.

17. To check the crystal settings choose Options for Target 'Target 1' by expanding the target 1 . Select the target field and set the crystal (XTAL) frequency to 11.0592 $\mathrm{MHz}$

18. To start a simulation session chooses Start/Stop Debug Session from the Debug pull-down menu.

19. During our simulation it displays all Ports by selecting from the I/O Ports pull down menu in the Peripherals menu. A tick on a pin means that it is at logic high. A blank on a pin is logic low.

Fig.1 Soil moisture sensor with microcontroller

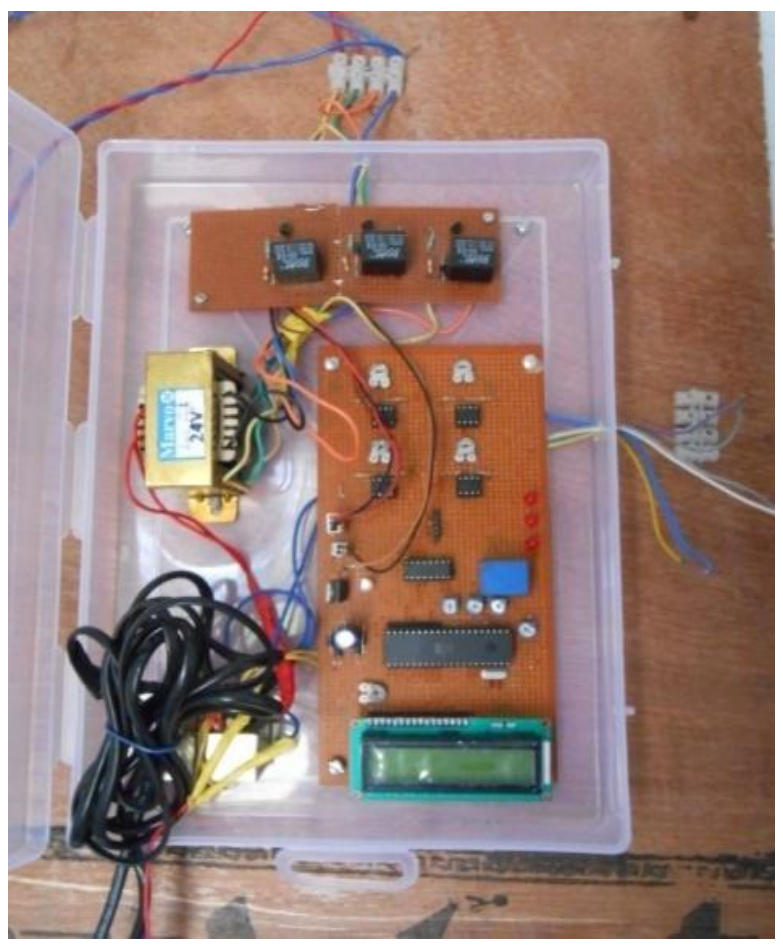

(a) Microcontroller based soil moisture sensor

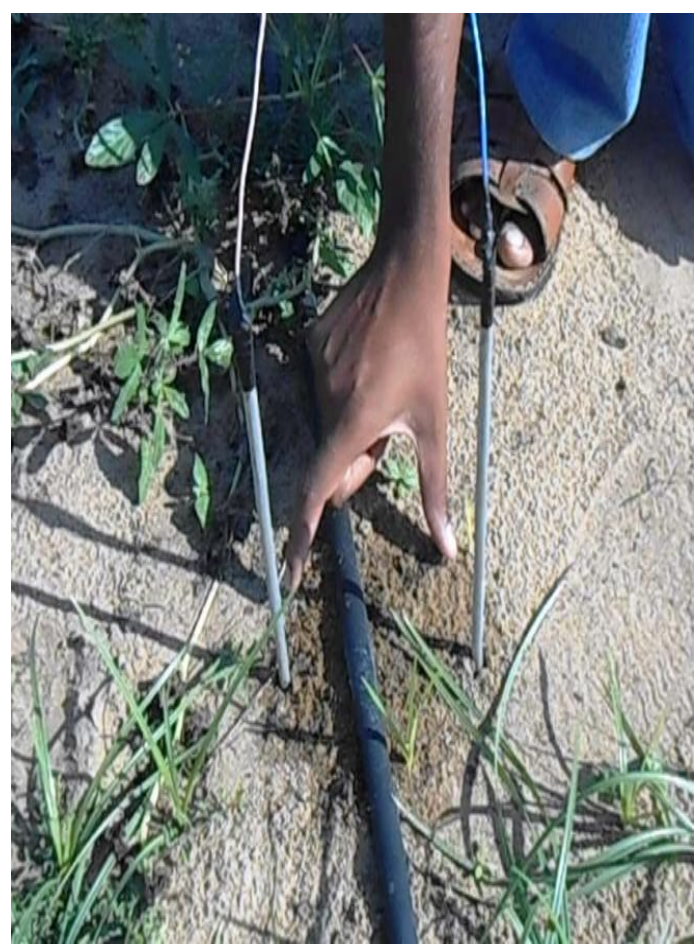

(b) Soil moisture aluminum probes 
Fig.2 Microcontroller unit

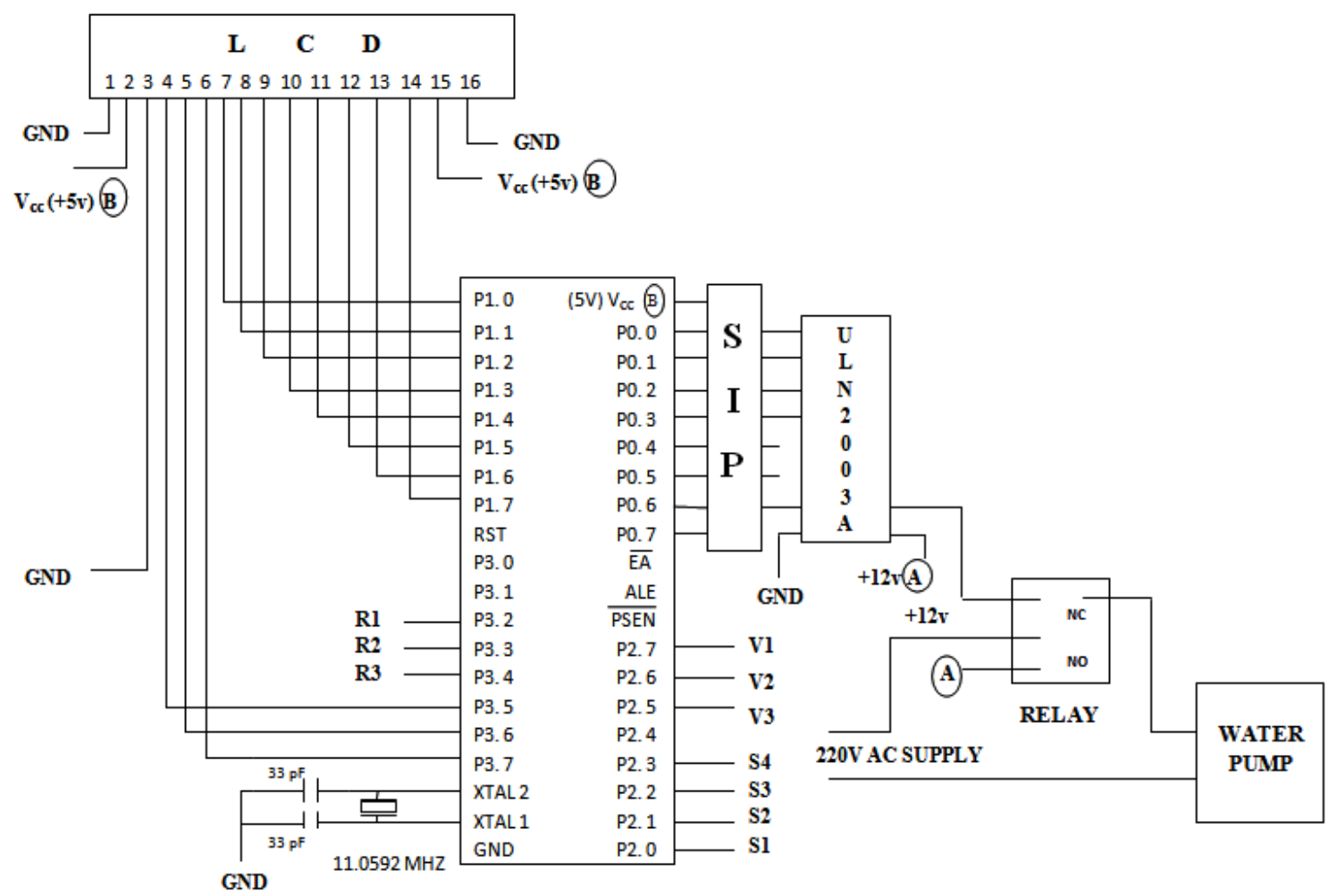

Fig.3 Power supply unit

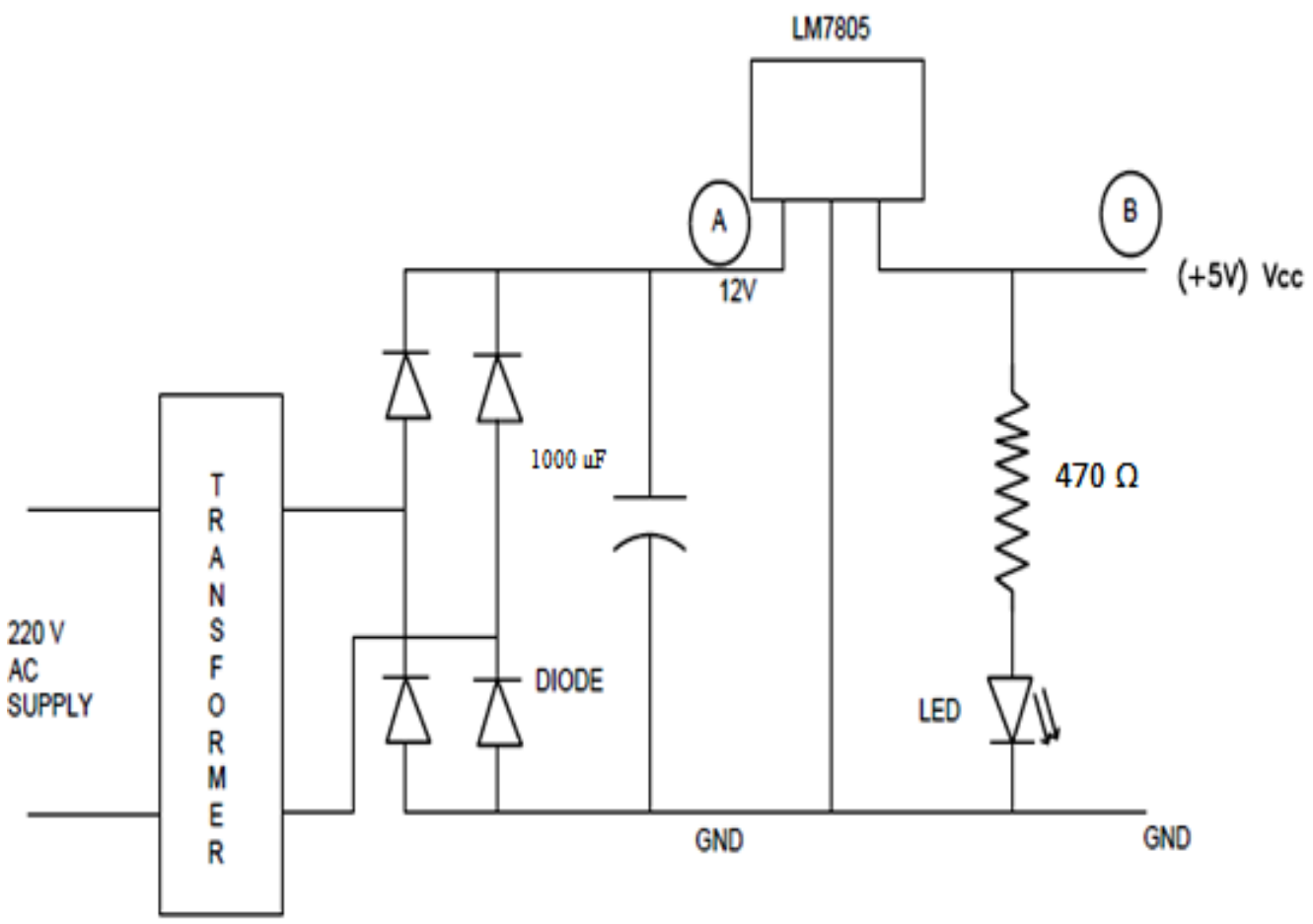


Fig.4 Sensor circuit diagrams
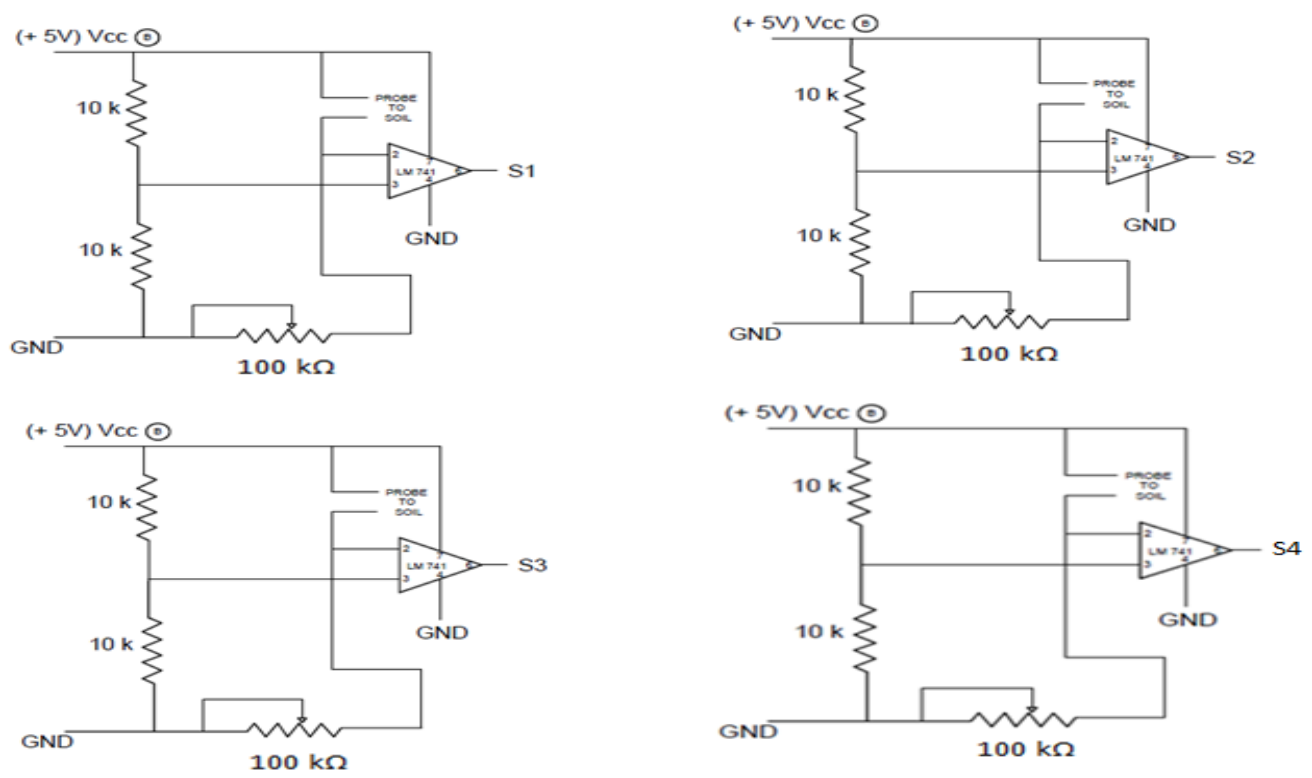

Fig.5 Power supply to solenoid valves

Solenoid Valve 3

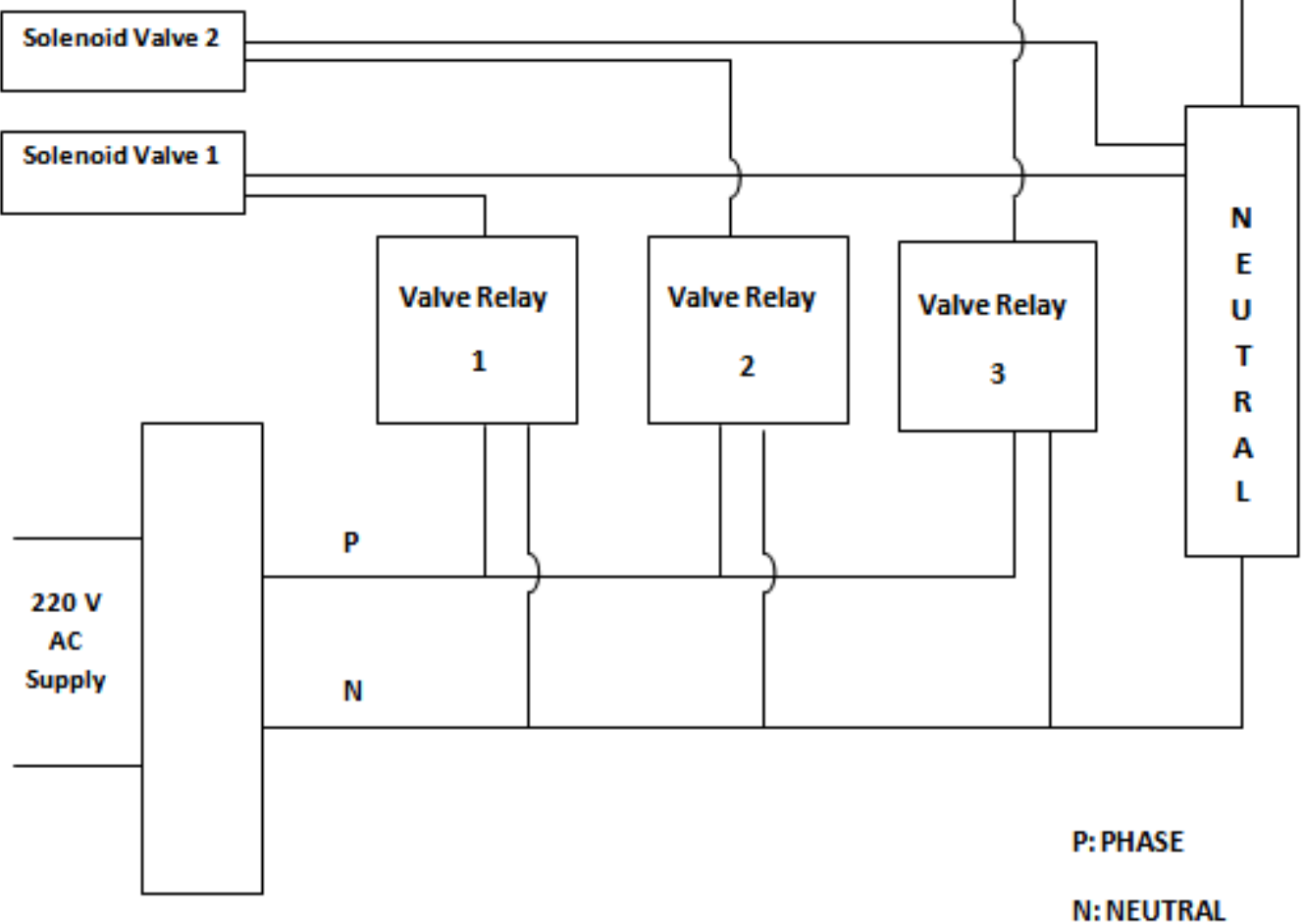


Fig.6 Block diagram of power supply

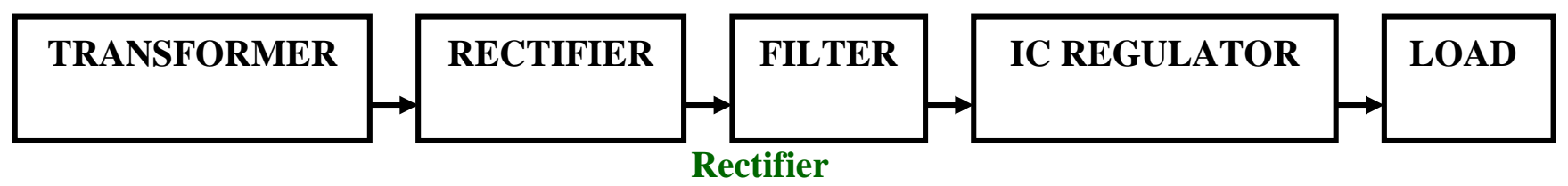

Fig.7 Main window of keil $\mu$ vision 3

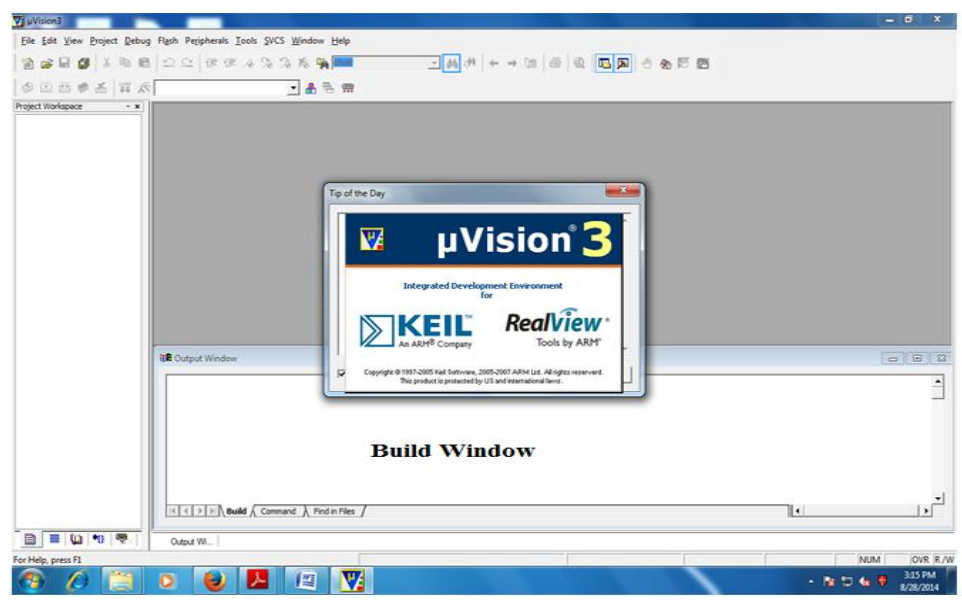

Table.1 Components list for the development of low cost microcontroller based Soil moisture sensor

\begin{tabular}{|l|}
\hline Components \\
\hline Transformers (2 No's) \\
\hline Voltage Regulator \\
\hline Op-amp (4 No's) \\
\hline Crystal oscillator \\
\hline Diode \\
\hline LED
\end{tabular}

\begin{tabular}{ll|}
\hline Resistor \\
\hline Capacitor \\
\hline LCD
\end{tabular}

LCD

Relay

Microcontroller

ULN

Water pump

Switches

Power cables

Connectors

Solenoid Valves

Aluminum Probes

\section{Specifications}

Step down transformer (220/12)

IC 7805

LM741

$11.0592 \mathrm{M} \mathrm{Hz}$

IN 4007

Red (700 nanometers), 470 ohm (for LED), $10 \mathrm{~K}$ (for sensors), potentiometer(100K) $1000 \mu \mathrm{f}$ (for Power supply)

$33 \mathrm{p} \mathrm{F}$ (for crystal oscillator)

$16 \times 2$ 220V/3-4A

AT89S52

ULN 2003 
Table.2 Actual water applied for sweet corn crop in different irrigation systems

\begin{tabular}{|c|c|c|c|c|c|}
\hline S.No. & Treatment & $\begin{array}{c}\text { Water applied } \\
\text { during sowing }(\mathbf{m m})\end{array}$ & $\begin{array}{c}\text { Water applied } \\
\text { during crop growth } \\
(\mathbf{m} \mathbf{m})\end{array}$ & $\begin{array}{c}\text { Total water } \\
\text { applied }(\mathbf{m m})\end{array}$ & $\begin{array}{c}\text { \% of water } \\
\text { saving }\end{array}$ \\
\hline $\mathbf{1}$ & Flood & 50 & 470 & 520 & - \\
\hline $\mathbf{3}$ & Single row drip & 50 & 282 & 332 & 36 \\
\hline
\end{tabular}

Table.3 Cob Characteristics for different irrigation treatments

\begin{tabular}{|c|c|c|c|c|c|}
\hline Treatment & $\begin{array}{c}\text { No. of kernel } \\
\text { rows/cob }\end{array}$ & $\begin{array}{c}\text { No. of } \\
\text { kernels/cob }\end{array}$ & $\begin{array}{c}\text { Cob diameter } \\
(\mathbf{c m})\end{array}$ & $\begin{array}{c}\text { Cob length } \\
(\mathbf{c m})\end{array}$ & $\begin{array}{c}\text { Individual fresh } \\
\text { cob weight }(\mathrm{g})\end{array}$ \\
\hline Flood irrigation & 16.0 & 656.8 & 5.15 & 20.26 & 367.6 \\
\hline Single row drip & 16.8 & 755.2 & 5.51 & 20.54 & 405.2 \\
\hline Paired row drip & 14.8 & 558.8 & 3.824 & 18.80 & 226.6 \\
\hline
\end{tabular}

Table.4 Water use efficiency of the sweet corn under different levels of the irrigation

\begin{tabular}{|c|c|c|c|c|}
\hline S.No & Treatments & $\begin{array}{c}\text { Yield } \\
\left(\mathrm{kg} \mathrm{ha}^{-1}\right)\end{array}$ & $\begin{array}{c}\text { Water applied } \\
(\mathbf{m m})\end{array}$ & $\begin{array}{c}\text { Water use efficiency } \\
(\mathbf{k g} / \mathbf{h a}-\mathbf{m m})\end{array}$ \\
\hline $\mathbf{1}$ & Flood irrigation & 7429 & 520 & 14.29 \\
\hline $\mathbf{2}$ & Single row drip & 7929 & 332 & 23.88 \\
\hline $\mathbf{3}$ & Paired row drip & 6476 & 332 & 19.51 \\
\hline
\end{tabular}

Now simulate the code with the following options that are available from the Debug pulldown menu: -
i. Go
ii. Stop
iii. Step into
iv. Step over
v. Run till cursor

20. Finally, configure the target option to ensure that a hex file is generated during the build process. Choose Project, Options for Target 'Target 1'. Select the Output tab and tick the 'Create Hex File' box. After this step rebuild the project for checking the errors.

\section{Flash magic software}

Burn the hex file to microcontroller using the Flash Magic software by the following steps.

Connect the burner to PC using serial communication port

Browse the hex file.

Now burn the hex file to microcontroller using send command.

\section{Crop water requirement applied in different irrigation methods}

The amount of water applied in flood irrigation system for sweet corn crop was based on CROPWAT data $(470 \mathrm{~mm})$ in addition to 50 $\mathrm{mm}$ water used at the time of sowing.

Hence, totally $520 \mathrm{~mm}$ of water was used in flood method. Where as in drip method, water applied is based on the operation of automatic soil moisture sensor. When the soil is reached to field capacity the irrigation was automatically stopped and the system used to get started giving irrigation, when the soil moisture is reached to $70 \%$ of field capacity. The authenticity of automation unit was cross 
checked by collecting soil samples near the moisture sensors and found the moisture content through gravimetric method for both the limits. The field capacity was found to be $8.47 \%$ and hence sensor will switch off automatically at moisture content of $8.16 \%$ and automatically switch on at moisture content of $5.8 \%$.

It was found that water applied for sweet corn crop in alternative days in both methods of drip system at the initial stage and daily from the development stage to one week before harvesting. The amount of water applied measured regularly with the help of timedischarge relation and total water applied in different irrigation systems was presented in Table 2. It was observed that $332 \mathrm{~mm}$ of water applied in drip instead of $520 \mathrm{~mm}$ in flood method for sweet corn and $36 \%$ water saved in drip method. And also yield response for the treatments, plant height, root depth and cob characteristics (Abdullah et al., 2003) were recorded in all three treatments as shown in Table 3.

\section{Water use efficiency}

It was found that water use efficiency is highest in single row drip method as $23.88 \mathrm{~kg} / \mathrm{ha}-\mathrm{mm}$ followed by paired row drip and flood method as 19.51 and $14.29 \mathrm{~kg} / \mathrm{ha}-\mathrm{mm}$ respectively as shown in Table 4. In paired row drip system, more water use efficiency observed than flood due to $36 \%$ water saving even though yield is less compared to flood method.

\section{References}

Abdullah, O., Mehmet, S and Gulgun, O.A. 2003. Deficit irrigation effects on sweet corn (Zea mays saccharata Sturt) with drip irrigation system in a semi-arid region I. Water-yield relationship. Agricultural Water Management. 61: 6374.

Boaz, A. 2015. Water scarcity a threat for Agriculture. Journal of Agriculture and Rural Development. 42(5): 42-44.

Divya, V and Umamakeswari, A. 2013. An intelligent irrigation system with voice commands and remote monitoring of field. Journal of Artificial Intelligence. 6(1): 101-106.

Mahir, D. and Semih O. 2011. A wireless application of drip irrigation automation supported by soil moisture sensors. Scientific Research and Essays. 6(7): 1573-1582.

Mulas, P., 1986. Developments in the automation of irrigation. Colture Protette. 15 (6), 17-19.

Noble, A., Hema, P.S., Saritha, E.K and Shinoj, S. 1999. Irrigation automation based on soil electrical conductivity and leaf temperature. Agricultural Water Management. 45: 145-157.

Prasad, K.S.S., Nitesh, K., Sinha, N.K and Kumar, P.S. 2012. Water-saving irrigation system based on automatic control by using GSM technology. Middle-East Journal of Scientific Research. 12(12): 1824-1827.

Schreiber, H.A., Stanberry, C.O and Henry Tucker. 1962. Irrigation and nitrogen effects on sweet corns row numbers at various growth stages. American Association for the Advancement of Science. 135(3509): 1135-1136.

\section{How to cite this article:}

Gowtham Deekshithulu, N.V., G. Ravi Babu, R. Ganesh Babu and Siva Ramakrishna, M. 2018. Development of Software for the Microcontroller Based Automated Drip Irrigation System Using Soil Moisture Sensor. Int.J.Curr.Microbiol.App.Sci. 7(01): 1385-1393.

doi: https://doi.org/10.20546/ijcmas.2018.701.169 